\title{
Removal of U ( VI) From Aqueous Solution By Effective Bio-Adsorbent From Walnut Shell And Cellulose Composites Stabilized Iron Sulfide Nanoparticle
}

\section{Huifang Wang}

Shaoxing University

Renrong Liu

Shaoxing University

Li Han

Shaoxing University

Baowei Hu

Shaoxing University

Muqing Qiu ( $\square$ qiumuqing@usx.edu.cn )

Shaoxing University

\section{Research Article}

Keywords: Removal, U(VI), Iron sulfide nanoparticle, Cellulose, Walnut shell

Posted Date: August 4th, 2021

DOl: https://doi.org/10.21203/rs.3.rs-725262/v1

License: (c) (1) This work is licensed under a Creative Commons Attribution 4.0 International License.

Read Full License 
2 from walnut shell and cellulose composites stabilized iron sulfide

3 nanoparticle

4

Huifang Wang, Renrong Liu, Li Han, Baowei Hu, Muqing Qiu*

School of Life Science, Shaoxing University, Huancheng West Road 508, Shaoxing, 312000, P. R. China

*Corresponding Author: Muqing Qiu, qiumuqing@usx.edu.cn

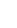

\section{Abstract}

FeS nanoparticles were easily aggregated and oxidized in the natural environment due to van der Waals forces between nanoparticles. Biochar could be used as a carrier to inhibit the agglomeration and oxidization of FeS nanoparticles. An efficient bio-adsorbent (CFeS-WS) from walnut shell (WS) and cellulose composites stabilized iron sulfide nanoparticle was synthesized by the modified method. It also was determined by SEM, EDS, XRD and FT-IR, respectively. The removal of U(VI) ions from aqueous solution by CFeS-WS were conducted. The reaction mechanism between CFeS-WS and U(VI) ions also were discussed in details. The experimental results were showed that the biochar successfully was supported with cellulose $/ \mathrm{FeS}$ composites (CFeS). CFeS-WS exhibited an excellent removal performance for U(VI) ions in solution. The adsorption process of $\mathrm{U}(\mathrm{VI})$ ions by CFeS-WS was more consistent with pseudo second-order kinetic model and Langmuir isotherm model. The proposed reaction mechanism of $\mathrm{U}(\mathrm{VI})$ ions removal by CFeS-WS mainly consisted of ion exchange reaction, reduction reaction, hydrogen bonding and functional group, and pore of adsorbent filling. Recycle experiment indicated that CFeS-WS was a cost-effective bio-adsorbent.

Keywords: Removal; U(VI); Iron sulfide nanoparticle; Cellulose; Walnut shell 


\section{Introduction}

For nuclear energy, uranium is the main fuel in the nuclear industry and the main component of nuclear waste (Ma et al. 2015, Sun et al. 2016, Zhang et al. 2021). Because of its low price and non-polluting advantages, it is considered to be one of the potential substitutes for fossil fuels in the future (Pegg 2015; Hao et al. 2021). However, Uranium also is radioactive and carcinogenic for a long time. Even a small amount of uranium may cause serious harm to human health and environment (Sun et al. 2014, Xu et al. 2015, Troyer et al. 2016). Therefore, the disposal of nuclear waste is a very challenging problem and an urgent problem that needs to be solved (Sheng et al. 2012, Qiu et al. 2021). According to the perspective of economic and practical efficiency advantages, adsorption technology has gradually attracted the attention of researchers (Tan et al. 2009, Wang et al. 2015, Qiu et al. 2018, Hu et al. 2019). Various adsorbents are applied into the treatment of radioactive wastewater (Chen et al. 2007, Yu et al. 2008, Sheng et al. 2014, Sun et al. 2015, Popel et al. 2016, Yao et al. 2018). Many adsorbents (such as carbon fibers, carbon nanotubes and graphene oxide et al.) have been applied into the removal of U(VI) from environment (Senanayake \& Idriss 2006, Hedhili et al. 2000, Hyun et al. 2012, Yu et al. 2016).

In recent years, the application of iron-based materials was studied because of their environmental friendliness and high treatment processing efficiency. Therefore, they have attracted the attention of many scholars (He et al. 2010). More and more researchers have begun to develop a variety of different iron-based materials to remove the radioactive uranium from wastewater (Shi et al. 2015, Sun et al. 2016, Qiu \& Huang 2017, Li et al. 2019). Ferrous sulfide (FeS) is one of the iron-based materials (Bostick et al. 2000). Compared with other iron-based materials, it is more effective in treating $\mathrm{U}(\mathrm{VI})$ wastewater due to the presence of $\mathrm{Fe}^{2+}$ ions and $\mathrm{S}^{2-}$ ions (Duan et al. 2016, Rehmana et al. 2018, Maity \& Agrawal 2007, Hussain et al. 2017, Hua \& Deng 2008). Because of their large volume ratio and high reactivity, nanoparticles are widely used to treat pollutants in sewage and soil (Cao et al. 2018, Wang et al. 2021). However, FeS nanoparticles are easily aggregated and oxidized in the natural environment due to van der Waals forces between nanoparticles. This 
reduces the reactivity between nanoparticles and pollutants. This reduces the contact area between nanoparticles and pollutants and thus affects the reactivity between them. This problem has become an important factor limiting the application of FeS nanoparticles into pollution treatment. It was very important to look for a suitable stabilizer to modify FeS nanoparticles.

Various techniques have been tested to overcome the shortcoming of $\mathrm{FeS}$ nanoparticles, such as silica, sepiolite, activated carbon and biochar et al. (Liu et al. 2011, Oliveira et al. 2014, Liang et al. 2016, Zhang et al. 2016, Wang et al. 2018). Compared with other materials, biochar presented some advantages. They were large specific surface area, high stability, low bulk density, strong adsorption capacity, low cost and simple operation (Qiu et al. 2017). As an emerging adsorbent, biochar had the advantages of wide sources of raw materials and low price, so it had huge application potential in uranium (VI) adsorption (Amuda et al. 2007, Veeramani et al. 2011, Yang et al. 2016). Biochar was a carbon-rich solid material, which was obtained under anoxic conditions. Biochar had attracted more and more attention due to its high efficient removal rate, novel porosity, high specific surface area and low cost. It had been proved that biochar could be considered as an effective material to eliminate U(VI) from aqueous solution (Zou et al. 2013, Hu et al. 2021). Additionally, biochar could be used as a carrier to inhibit the agglomeration and oxidization of $\mathrm{FeS}$ nanoparticles. Therefore, it was important to stabilize iron sulfide nanoparticle composite with a stabilizer before being supported by biochar. Furthermore, the removal of $\mathrm{U}(\mathrm{VI})$ ions in solution by biochar stabilized iron sulfide nanoparticle composite are reported relatively few.

The overall objective of this work was to synthesize an efficient bio-adsorbent(CFeS-WS) from walnut shell(WS) and cellulose composites stabilized iron sulfide nanoparticle(FeS), and elaborate the reaction mechanism between CFeS-WS and pollutant. The characterization of CFeS-WS was determined by SEM, EDS, XRD and FT-IR, respectively. The U(VI) ions were selected as contaminant to test the removal rate. The specific objectives were to: (1) synthesize and characterize of CFeS-WS; (2) assess the influences of operating parameters on the removal rate of 
U(VI) in solution; (3) describe reaction mechanism between U(VI) ions and CFeS-WS.

\section{Materials and methods}

\section{Chemical reagents}

The walnut shell(WS) was obtained from the farm Fuzhou City, Jiangxi Province, P.R. China. In this experiment, chemical reagents all were analytical grade and used without further purification. Chemical reagents, such as cellulose, $\mathrm{FeSO}_{4} \cdot 7 \mathrm{H}_{2} \mathrm{O}$, $\mathrm{Na}_{2} \mathrm{~S} \cdot 9 \mathrm{H}_{2} \mathrm{O}$ and $\mathrm{UO}_{2}\left(\mathrm{NO}_{3}\right)_{2} \cdot 6 \mathrm{H}_{2} \mathrm{O}$, were purchased at Shanghai McLin Chemical Reagent Co. Ltd. (Shanghai, China). Moreover, they all were analytical grade. Under the magnetic stirring condition, the deionized water was aerated by nitrogen for about $30 \mathrm{~min}$. Then, the anaerobic deionized water was obtained.

\section{Preparation of adsorbents}

According to the modified method (Lyu et al. 2018), the preparation of biochar from walnut shell, FeS nanoparticle and CFeS-WS were prepared, respectively. Preparation of biochar derived from walnut shell, FeS nanoparticles and CFeS-WS were shown in Supporting Information. In a word, biochar from walnut shell were added into 250 $\mathrm{mL}$ Erlenmeyer flask containing of $\mathrm{FeSO}_{4}$. They were stirred for $30 \mathrm{~min}$. Then, cellulose and $\mathrm{Na}_{2} \mathrm{~S}$ were added, mixed with them, stirred for $30 \mathrm{~min}$ again. In the process of preparation, they were conducted under magnetic stirring condition and continuous aerating nitrogen. Next, the mixture solution was placed at the temperature of $25^{\circ} \mathrm{C}$ for $48 \mathrm{~h}$, freeze-dried for $12 \mathrm{~h}$, washed for three times with anaerobic deionized water, and freeze-dried for $12 \mathrm{~h}$. The efficient bio-adsorbent of CFeS-WS was obtained.

\section{Characterization}

SEM (SIGMA, Germany) was used for observing the surface morphology and structure of adsorbents. FT-IR spectrometer (Nexus 670, Madison) in the wave number range of $400-4000 \mathrm{~cm}^{-1}$ was used for testing the surface functional groups of 
adsorbents. D/Max-IIIA Powder X-ray Diffractomer (Rigaku Corp., Japan) was used to analyze XRD of adsorbents.

\section{Batch experiments}

The batch experiments were conducted at a shaker. Added $100 \mathrm{~mL} \mathrm{U}(\mathrm{VI})$ ions solution into $250 \mathrm{~mL}$ of Erlenmeyer flask. Then, adsorbents were put into $250 \mathrm{~mL}$ of Erlenmeyer flask. The $\mathrm{pH}$ in solution was adjusted by $0.2 \mathrm{~mol} / \mathrm{L} \mathrm{NaOH}$ or $0.2 \mathrm{~mol} / \mathrm{L}$ $\mathrm{HCl}$, respectively. Next, flask was sealed by bottle cap, which was placed in the shaker at $150 \mathrm{rpm}$ and constant temperature. After the entire experimental process reached equilibrium, the supernatant was sampled by filter filtration. The U(VI) ions in solution was analyzed by method of UV-vis spectrophotometry (Liu et al. 2018). Then, the residual solution was centrifuged at $5000 \mathrm{rpm}$ for $10 \mathrm{~min}$. The obtained sediment also was determined.

In order to describe the removal mechanisms and the characteristic of adsorption process, the influences parameters (for example, initial of $\mathrm{pH}$ value in solution, initial concentration of $\mathrm{U}(\mathrm{VI})$ ions, reaction time and temperature) on the removal rate of U(VI) ions in solution by adsorbents were tested. The calculation of the removal rate $(R(\%))$ and uptake capacity $(q(\mathrm{mg} / \mathrm{g}))$ were shown in Supporting Information.

\section{Results and discussion}

\section{Characterization of composites}

The SEM images of biochar, FeS nanoparticle, FeS-WS and CFeS-WS were showed in Fig.1. From Fig.1A, it could be seen that biochar was irregular shape and rough surface. However, there were very few pores on the surface of biochar. FeS nanoparticles were aggregated flocculent shape and looked like snowflake or flower (Fig.1B). Fig.1C showed clearly that the discrete FeS nanoparticles were observed on the irregular and rough surface of biochar. It also indicated that the like snowflake FeS nanoparticles were appeared on the surface of biochar, and were connected with biochar. The existence of biochar could inhibit the agglomeration of FeS 
nanoparticles in a certain extent. However, it also could be found that the amount of FeS nanoparticles loaded on biochar was small. The SEM image of CFeS-WS was shown in Fig.1D. It depicted that the surface of biochar was covered by a large number of fine particles. It could be concluded that the particles on the surface of biochar were FeS nanoparticles. The biochar successfully was loaded with cellulose and FeS nanoparticles composites. The cellulose and biochar effectively prevent the agglomeration of $\mathrm{FeS}$ nanoparticles. It would improve the ability to remove pollutants.
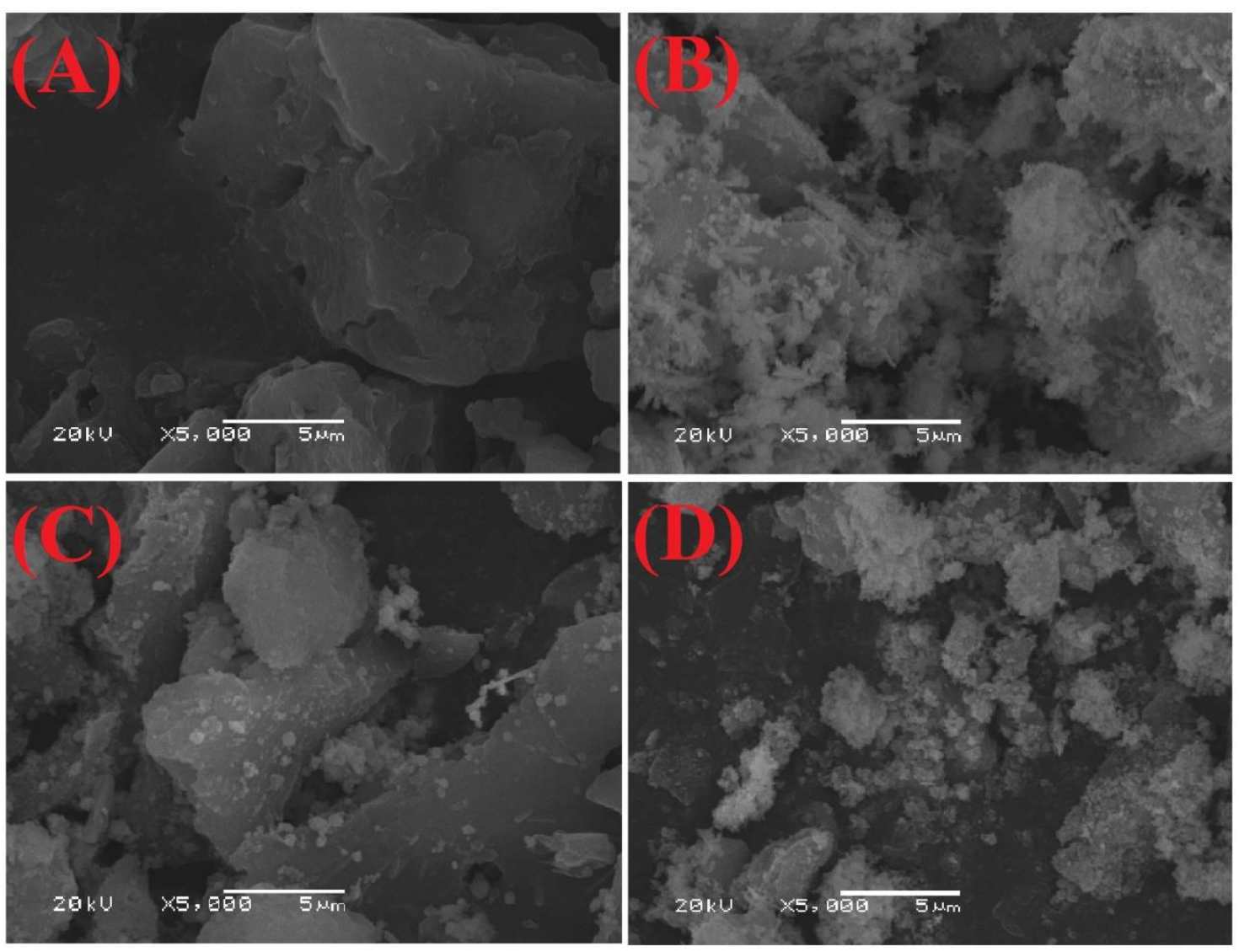

Fig.1 SEM images of biochar(A), FeS nanoparticles(B), FeS-WS(C) and CFeS-WS(D)

EDS layered images and EDS spectrum of biochar, FeS nanoparticles, FeS@biochar and CFeS-WS were depicted in Fig.2. It clearly indicated that FeS nanoparticles were embedded inside cellulose-FeS@biochar composites. For biochar, there were two obvious peaks corresponding to two elements of $\mathrm{C}(61.77 \%)$ and $\mathrm{O}(38.23 \%)$. Furthermore, the two elements of $\mathrm{Fe}(4.68 \%)$ and $\mathrm{S}(0.71 \%)$ were observed for 
CFeS-WS (Fig.2D). This result revealed that biochar as a skeleton material was loaded by $\mathrm{Fe}$ and $\mathrm{S}$ elements evenly. There were some $\mathrm{FeS}$ nanoparticles on the surface of biochar. The FeS nanoparticles were attached on the surface of biochar uniformly due to the large surface area of the biochar and the dispersibility of CFeS-WS. In other words, the preparation of CFeS-WS successfully was obtained again. This result was consistent with the results of Fig.1. FT-IR spectra and XRD patterns of biochar, FeS nanoparticles, FeS-WS and CFeS-WS were shown in Fig.3.

For biochar, five characteristic peaks were appeared at wavelengths of 563, 1051, 1373, 2330 and $3435 \mathrm{~cm}^{-1}$, respectively (Fig.3A). They were attributed to the vibration of alkoxy $\mathrm{C}-\mathrm{O}$, carboxyl $\mathrm{O}=\mathrm{C}-\mathrm{O}, \mathrm{C}=\mathrm{C}, \mathrm{C} \equiv \mathrm{C}$ and $-\mathrm{OH}$ functional groups (Devi \& Saroha 2014). For FeS-WS and CFeS-WS, the other functional groups were observed except for $\mathrm{C} \equiv \mathrm{C}$ functional groups. It might be the reason that biochar interacted with FeS nanoparticles. XRD patterns (B) of biochar, FeS nanoparticles, FeS-WS and CFeS-WS were depicted in Fig.3B. For biochar, a characteristic diffraction peak was appeared at $22.1^{\circ}$. It should be characteristic peak of biochar (Yen et al. 2011, Nguyen \& Pho, 2014, Zhang et al. 2015). For FeS nanoparticle, eight characteristic diffraction peaks were observed. They were assigned to the (101), (004), (200), (110), (204), (205), (303) and (222) planes of the FeS (JCPDS No. 23-1120). It could be proved that the pure crystalline was formed during the preparation process (Bacik et al. 2012, Lyu et al. 2016). 

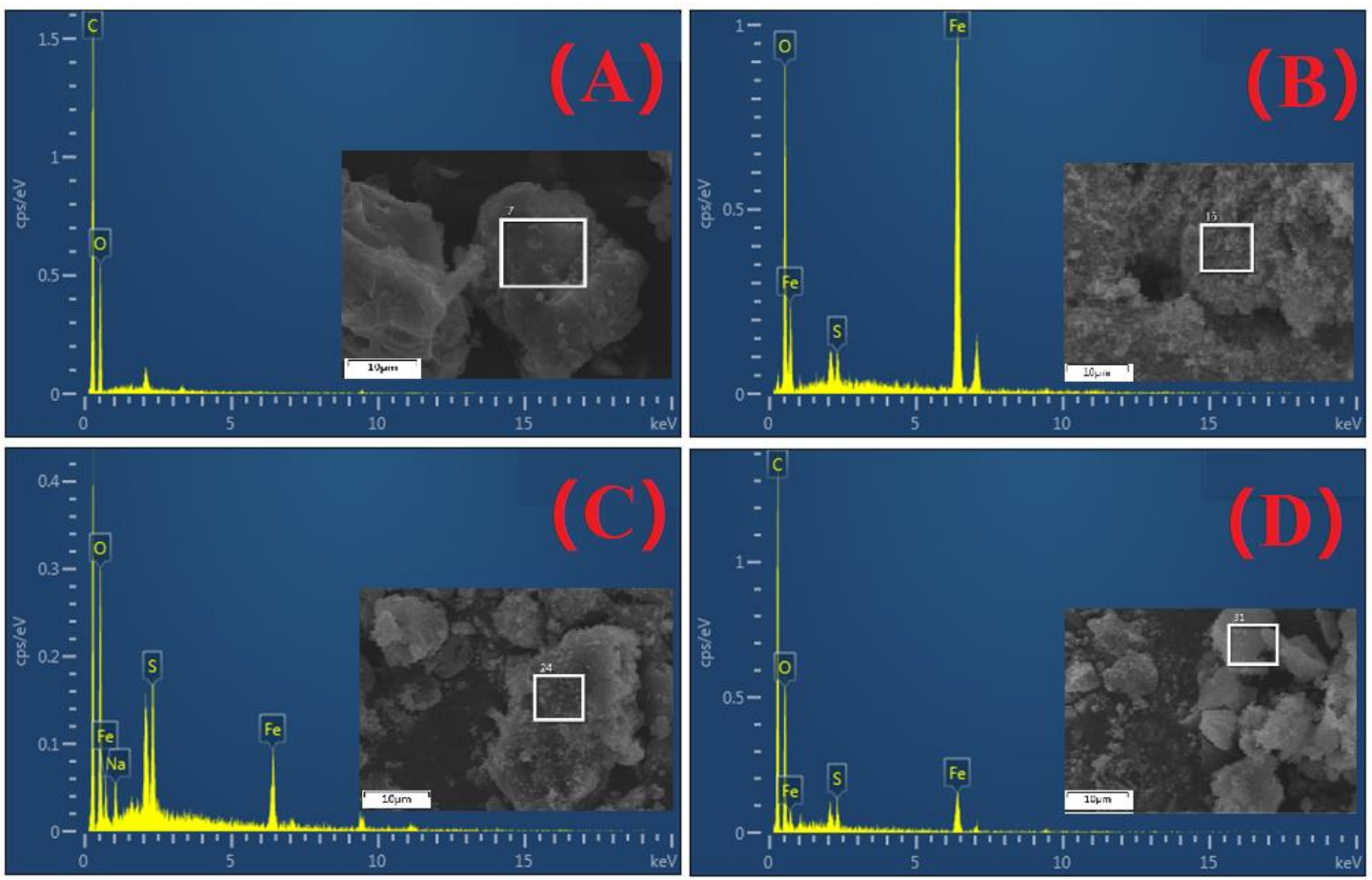

Fig.2 EDS layered images and EDS spectrum of biochar (A), FeS nanoparticles (B), FeS-WS (C) and CFeS-WS (D)
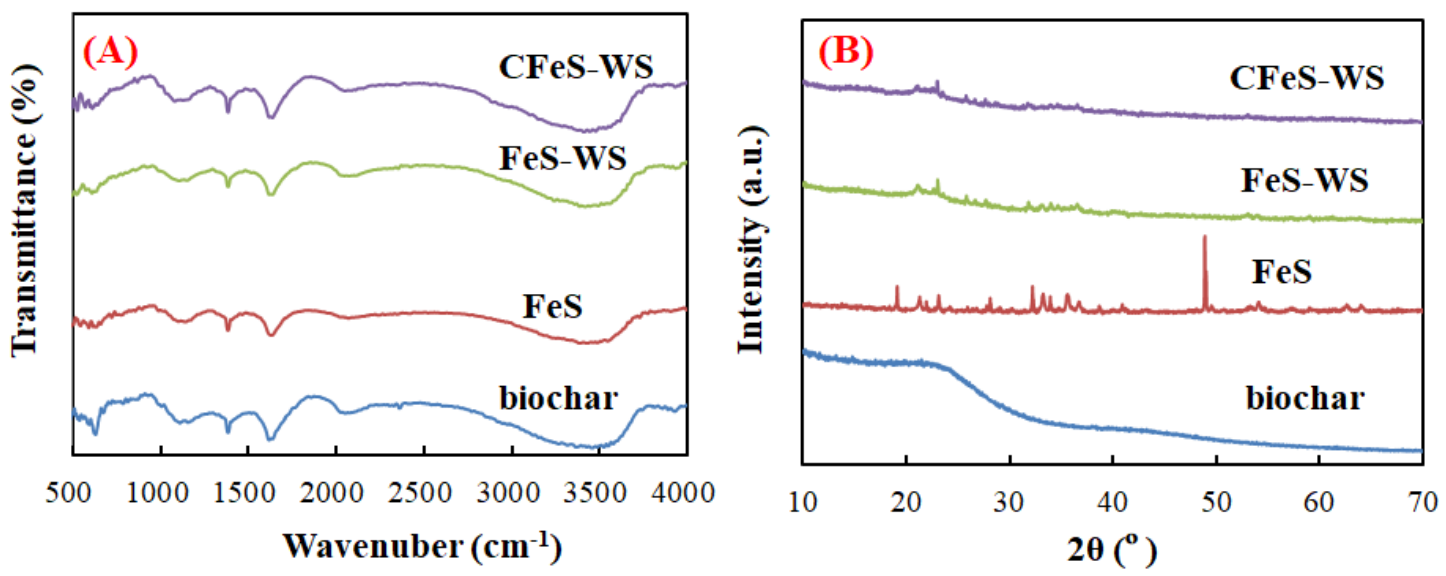

Fig.3 FT-IR spectra (A) and XRD patterns (B) of biochar, FeS nanoparticles, FeS-WS and CFeS-WS

\section{Effects of operational parameters on removal of U(VI) ions}

195 The value of $\mathrm{pH}$ was an important operational parameter in the adsorption process of $\mathrm{U}(\mathrm{VI})$ ions by $\mathrm{CFeS}-\mathrm{WS}$. The influence of $\mathrm{pH}$ in solution on $\mathrm{U}(\mathrm{VI})$ ions removal was 
tested with a different $\mathrm{pH}$ ranged from 2 to 12 . As shown from Fig.4A, it depicted that the removal rate of $\mathrm{U}(\mathrm{VI})$ ions was increasing with the increasing of $\mathrm{pH}$ at first stage. When $\mathrm{pH}$ in solution was ranged from 4 to 8 , the removal rate of $\mathrm{U}(\mathrm{VI})$ ions reached maximum adsorption. Subsequently, the removal rate of $U(V I)$ ions begun to decrease along with the increasing of $\mathrm{pH}$ in solution. This result was related to the species distribution of U(VI) ions in aqueous solution. The species distribution of U(VI) ions at different $\mathrm{pH}$ were shown in Fig.7 of Supplement materials. When value of $\mathrm{pH}$ in solution was less than 2.0, the main form of $\mathrm{U}(\mathrm{VI})$ ions in solution was $\mathrm{UO}_{2}^{2+}$ ions. Along with the value of $\mathrm{pH}$ in solution increased, the concentration of $\mathrm{UO}_{2}^{2+}$ ions began to decrease. The concentration of $\left(\mathrm{UO}_{2}\right)_{2}(\mathrm{OH})_{2}^{2+}$ and $\mathrm{UO}_{2}(\mathrm{OH})^{+}$in solution were increasing slowly. When $\mathrm{pH}$ was 7.0, the main form of U(VI) ions in solution was $\left(\mathrm{UO}_{2}\right)_{2}(\mathrm{OH})_{2}^{2+}, \mathrm{UO}_{2}(\mathrm{OH})^{+}$and $\mathrm{UO}_{2}(\mathrm{OH})_{2}$, respectively. When the value of $\mathrm{pH}>7.0$, the main form of $\mathrm{U}(\mathrm{VI})$ ions in solution was $\mathrm{UO}_{2}(\mathrm{OH})_{2}, \mathrm{UO}_{2}(\mathrm{OH})_{3}^{-}$, $\left(\mathrm{UO}_{2}\right)_{3}(\mathrm{OH})^{7-}$ and $\mathrm{UO}_{2}(\mathrm{OH})_{4}^{2-}$, respectively. The value of $\mathrm{pH}$ in solution had an important influence on the species distribution of U(VI) ions.

The contact time played a role in the adsorption process of U(VI) ions in solution (Fig.4B). It could be found that the removal rate of U(VI) ions increased quickly with the increasing of contact time. However, the removal rate of U(VI) ions begun to increase very slowly as contact time reached $100 \mathrm{~min}$. Subsequently, the removal rate of U(VI) ions increased very little. This might be the reason that there were a lot of vacancies on the surface of the adsorbent at the beginning of adsorption process. As the adsorption process progressed further, the vacancy available for adsorption decreased gradually. The initial concentration of U(VI) ions in solution had an important effect on the removal rate (Fig.4C). It depicted that the removal rate decreased with the increasing of initial concentration. This might be this reason that the adsorption sites on the surface of adsorbent were not saturated at low concentration. Furthermore, under the driving force of the concentration gradient, the adsorption capacity of adsorbent also was increased (Nguyen \& Pho 2014, Zhang et al. 2016). These experimental results confirmed that concentration of U(VI) had an important effect on the removal rate of $\mathrm{U}(\mathrm{VI})$ ions in solution. The reaction 
temperature was benefit to enhance the removal rate of U(VI) ions by $\mathrm{CFeS}-\mathrm{WS}$ (Fig.4D). The removal rate was increasing with an increase of the reaction temperature.
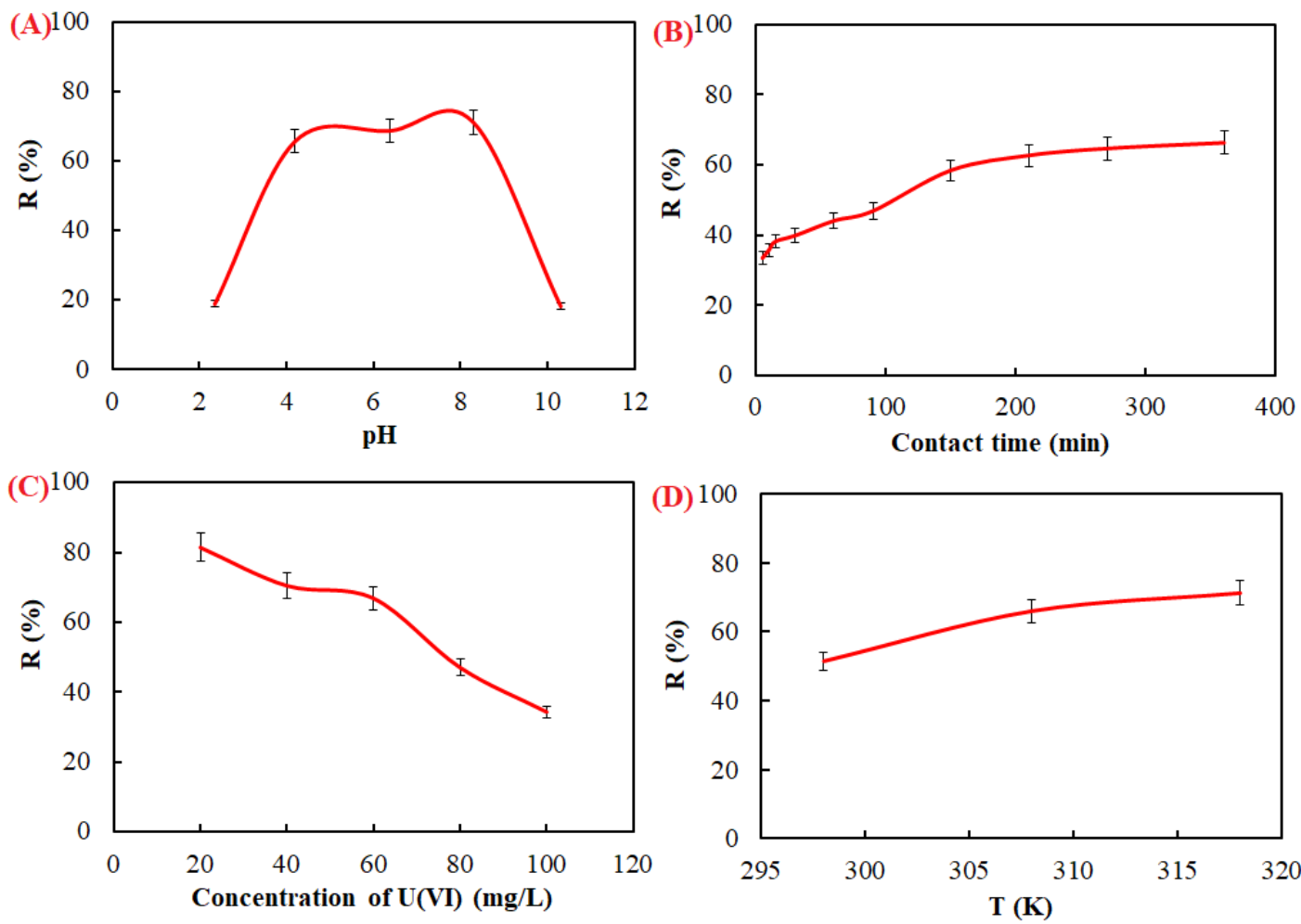

Fig.4 Effects of operational parameters on U(VI) ions removal in solution (A: pH; B: contact time; $\mathrm{C}$ : concentration of $\mathrm{U}(\mathrm{VI})$ and temperature)

\section{Adsorption kinetics, adsorption isotherms and thermodynamic}

In this study, pseudo first-order kinetic model and pseudo second-order kinetic model were used for the calculation of kinetic data (Leite et al. 2017). Pseudo first-order kinetic model and Pseudo second-order kinetic model were shown Supporting Information. Kinetics curves of U(VI) ions in solution onto CFeS-WS were described as Fig.5A-B.

The results were shown that the correlation coefficient of pseudo second-order kinetic model $\left(\mathrm{R}^{2}=0.9937\right)$ was higher than that of pseudo first-order kinetic model $\left(\mathrm{R}^{2}=0.9792\right)$. It was suggested that the order of adsorption process of $\mathrm{U}(\mathrm{VI})$ ions by

CFeS@biochar should be a chemical reaction. 
Adsorption isotherms could describe the relationship between the degree of accumulation of adsorbate onto an adsorbent surface to the concentration of adsorbate at constant temperature. In this research, the Langmuir isotherm model and Freundlich isotherm model were used to fit the adsorption data in order to display the adsorption behavior of U(VI) ions in solution onto CFeS-WS. Langmuir isotherm model and Freundlich isotherm model were shown Supporting Information.
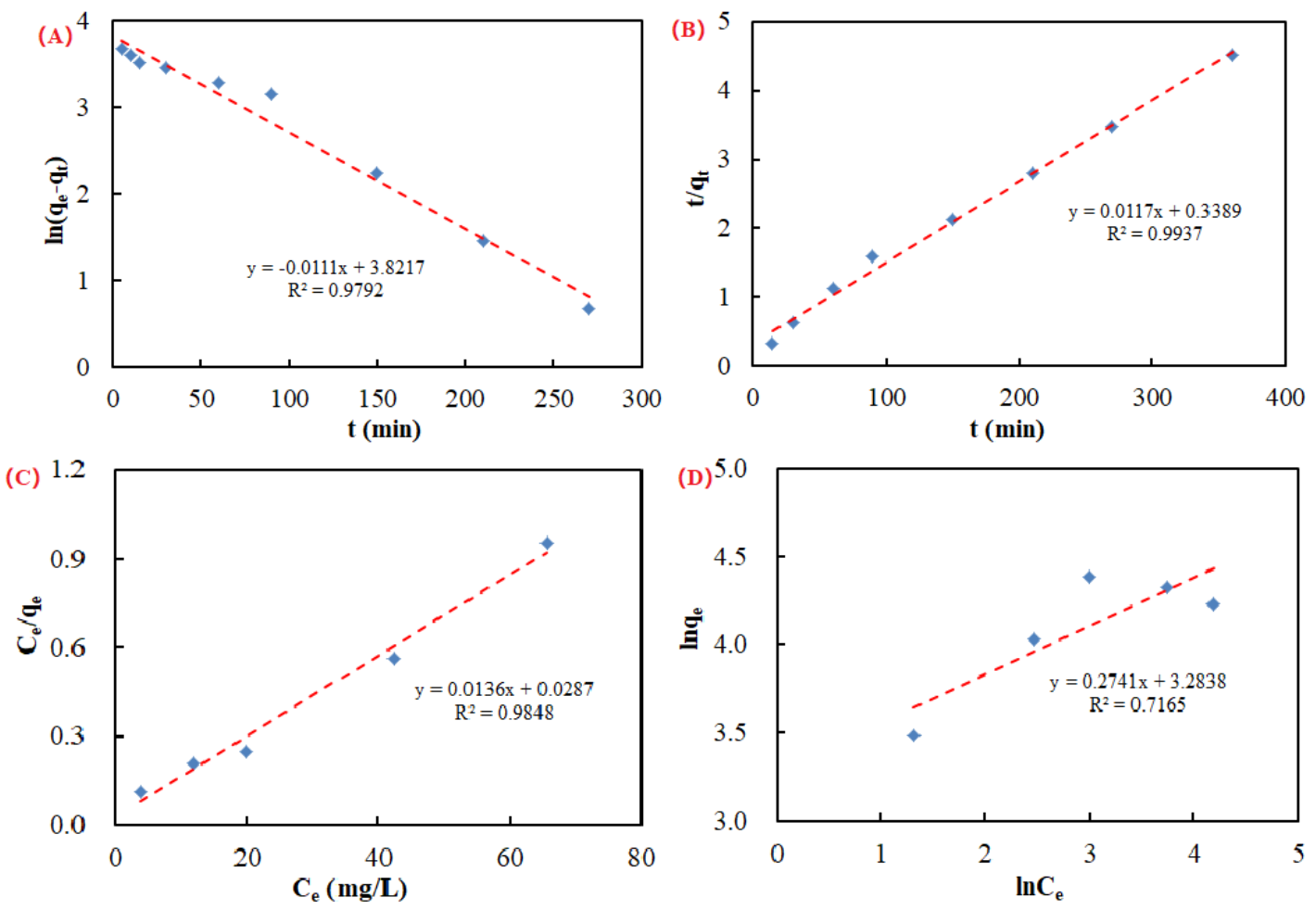

Fig.5 The kinetic adsorption and the adsorption isotherm for U(VI) by CFeS-WS (pseudo first-order kinetic model (A), pseudo second-order kinetic model (B), Langmuir isotherm model (C) and Freundlich isotherm model (D)).

The adsorption isotherms of $\mathrm{U}(\mathrm{VI})$ ions in solution onto CFeS-WS were given in Fig.5C-D. According to the correlation coefficients, it was showed that the adsorption process of U(VI) ions by CFeS-WS was more consistent with Langmuir isotherm model $\left(\mathrm{R}^{2}=0.9848\right)$. It also indicated that the value of $\mathrm{q}$ fitted by Langmuir isotherm model was closer to the adsorption experimental data.

In order to explore further mechanism of $\mathrm{U}(\mathrm{VI})$ uptake, thermodynamic parameters 
are evaluated to determine the spontaneity of the reaction. Calculation of

264 thermodynamic parameters was shown in Supporting Information. $\Delta H^{0}$ and $\Delta S^{0}$ were calculated from the slope and the intercept respectively. The results of calculation were listed in Table 1.

Table 1 Thermodynamic parameters of U(VI) removal by CFeS-WS

\begin{tabular}{|c|c|c|c|c|c|}
\hline \multicolumn{3}{|c|}{$\Delta G^{0}(\mathrm{~kJ} / \mathrm{mol})$} & \multirow{2}{*}{$\Delta H^{0}(\mathrm{~kJ} / \mathrm{mol})$} & \multirow{2}{*}{$\begin{array}{l}\Delta S^{0} \\
(\mathrm{~J} / \mathrm{mol} / \mathrm{K})\end{array}$} & \multirow{2}{*}{$\mathrm{R}^{2}$} \\
\hline $298(\mathrm{~K})$ & $308(\mathrm{~K})$ & $318(\mathrm{~K})$ & & & \\
\hline-3.48 & -5.45 & -8.11 & 231.15 & 60.65 & 0.9912 \\
\hline
\end{tabular}

It showed that the values of $\Delta G^{0}$ were all negative. It indicated that the adsorption process of $\mathrm{U}(\mathrm{VI})$ ions in solution onto $\mathrm{CFeS}-\mathrm{WS}$ was a spontaneous process under experimental conditions. The value of $\Delta G^{0}$ decreased as the reaction temperature increased. It depicted that the increase of reaction temperature was conductive to the reaction. The value of $\Delta H^{0}$ was $231.15 \mathrm{~kJ} / \mathrm{mol}$ and the value of $\Delta S^{0}$ was 60.65 $\mathrm{J} / \mathrm{mol} / \mathrm{K}$. It indicates that the adsorption process of $\mathrm{U}(\mathrm{VI})$ ions was an endothermic process. The system had a higher level of confusion.

\section{Proposed reaction mechanism}

According to the characterization of CFeS-WS, it could be concluded that there were a lot of FeS nanoparticles on the surface of CFeS@ biochar composites. Additionally, there also were a lot of alkoxy $\mathrm{C}-\mathrm{O}$, carboxyl $\mathrm{O}=\mathrm{C}-\mathrm{O}, \mathrm{C}=\mathrm{C}, \mathrm{C} \equiv \mathrm{C}$ and $-\mathrm{OH}$ functional groups on the surface of CFeS-WS. Furthermore, they also were irregular shape and rough surface. Therefore, the following reaction mechanism in this research could be suggested. It could be depicted at Fig.6. 


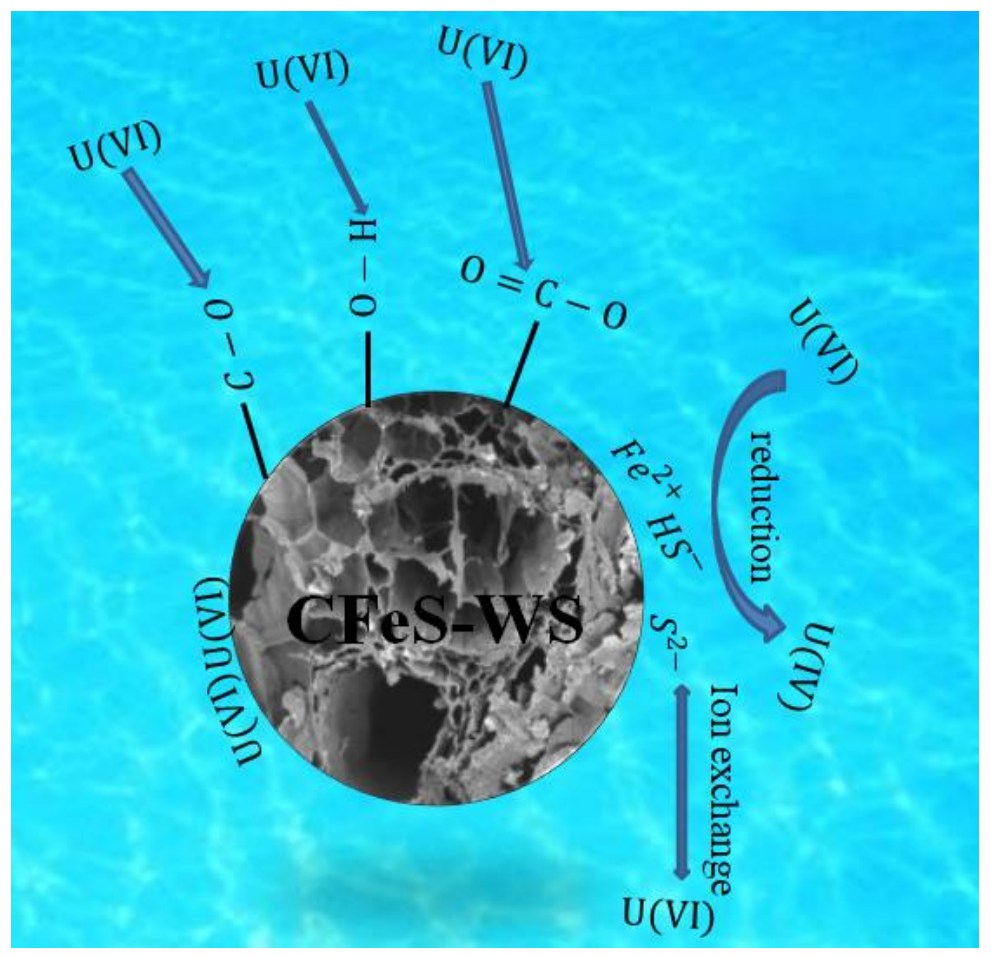

Fig.6 The proposed reaction mechanism

As shown form Fig.6, it indicated that the reaction mechanism of U(VI) removal by CFeS-WS mainly consisted of ion exchange reaction, reduction reaction, hydrogen bonding and functional group, and pore of adsorbent filling. The related chemical reactions were as following (Hyun et al. 2012).

$\mathrm{U}_{2}^{2+}+\equiv \mathrm{FeS} \Leftrightarrow \equiv S^{2-}-U O_{2}^{2+}+F e^{2+}$

$$
\equiv S^{2-}-U O_{2}^{2+} \Leftrightarrow S^{0}(s)-U O_{2}(s)
$$

$$
\mathrm{UO}_{2}^{2+}+H S^{-} \Leftrightarrow U O_{2}(s)-S^{0}(s)+H^{+}
$$

Eqn.10-13 indicated that $\mathrm{UO}_{2}^{2+}$ could be adsorbed on the surface of $\mathrm{FeS}$ nanoparticles through an ion exchange reaction. Then, U(VI) ions were reduced by $S^{2-}$ ions and $H S^{-}$ions, respectively. $S^{2-}$ ions and $H S^{-}$ions all were released from the dissolution of $\mathrm{FeS}(\mathrm{s})$.

There were a lot of alkoxy $\mathrm{C}-\mathrm{O}$, carboxyl $\mathrm{O}=\mathrm{C}-\mathrm{O}, \mathrm{C}=\mathrm{C}, \mathrm{C} \equiv \mathrm{C}$ and $-\mathrm{OH}$ functional 
groups on the surface of CFeS@ biochar composites. U(VI) ions in solution could be adsorbed through hydrogen bonding and functional groups. Additionally, a lots of adsorption location could be observed on the surface of CFeS-WS composites. It could be adsorb the $\mathrm{U}(\mathrm{VI})$ through pore of adsorbent filling.

In a word, the reaction mainly mechanism of U(VI) removal by CFeS-WS consisted of ion exchange reaction, reduction reaction, hydrogen bonding and functional group, and pore of adsorbent filling.

\section{Recycle experiment}

The ability of recycle was very important for the efficient bio-adsorbent in order to improve the economic value of the reaction process. The adsorption experiment was carried out at $\mathrm{pH} 6.0,40 \mathrm{mg} / \mathrm{L}$ of $\mathrm{U}(\mathrm{VI})$ concentration, $0.05 \mathrm{~g}$ of CFeS-WS, contact time of $6 \mathrm{~h}$, temperature of $318 \mathrm{~K}$ and $150 \mathrm{rpm}$. The $0.1 \mathrm{~mol} / \mathrm{L} \mathrm{H}_{2} \mathrm{SO}_{4}$ was used to desorb U(VI) ions from the surface of the adsorbent. Performance of CFeS-WS was evaluated according to five consecutive recycles of adsorption-desorption. The experimental results were shown in Fig.7.

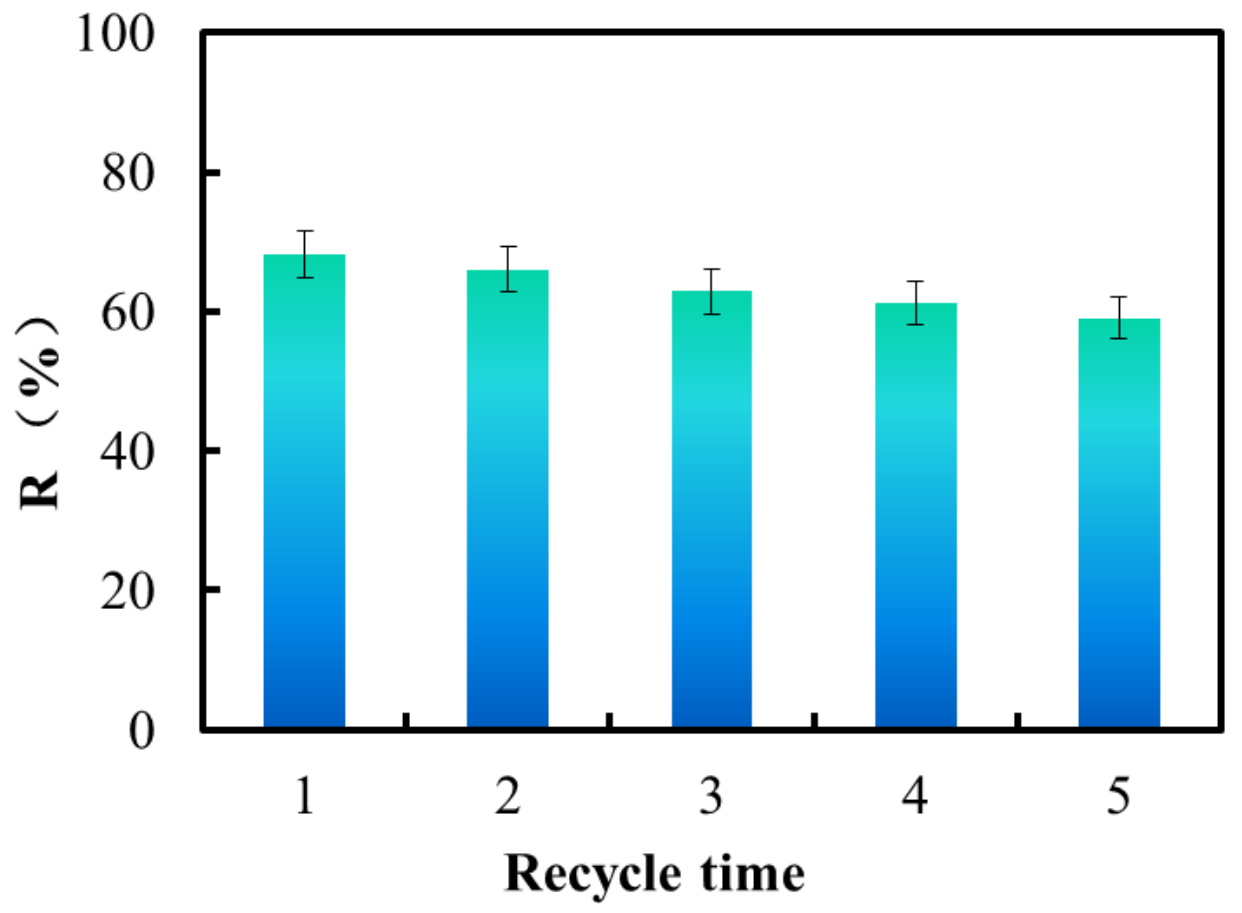

Fig.7 The recycle time of CFeS-WS for removal of U(VI) ions in solution 
As from Fig.7, it could be found that during the five consecutive recycles of adsorption-desorption, the removal rate of $\mathrm{U}(\mathrm{VI})$ ions was $68.12 \%, 66.03 \%, 62.83 \%$, $61.27 \%$ and $59.06 \%$, respectively. It could be concluded that the chemical stability of CFeS-WS was very well. CFeS-WS was a cost-effective bio-adsorbent.

\section{Conclusions}

An efficient bio-adsorbent from walnut shell stabilized iron sulfide nanoparticle composites were prepared. The biochar of walnut shell successfully was loaded by cellulose and FeS nanoparticles composites. The cellulose and biochar could prevent effectively the agglomeration of FeS nanoparticles. The adsorption process of U(VI) ions by $\mathrm{CFeS}$-WS was more consistent with Langmuir isotherm model and pseudo second-order kinetic model. The adsorption process of U(VI) ions in solution onto CFeS-WS was a spontaneous process under experimental conditions. The adsorption process of U(VI) ions was an endothermic process. The system had a higher level of confusion. The proposed reaction mechanism of $\mathrm{U}(\mathrm{VI})$ ions removal by CFeS-WS mainly consisted of ion exchange reaction, reduction reaction, hydrogen bonding and functional group, and pore of adsorbent filling. CFeS-WS was a cost-effective bio-adsorbent.

\section{Ethical Approval}

This section is "not applicable" for this study.

\section{Consent to Participate}

Not applicable.

\section{Consent to Publish}

All authors reviewed and approved the manuscript for publication.

\section{Authors Contributions}

Huifang Huang and Renrong Liu designed the experiment, and Li Han performed the 
experiment. Muqing Qiu processed the experimental data and wrote this article. Baowei Hu revised this paper.

\section{Funding}

This work is financially supported by Natural Science Foundation of Zhejiang Province, China (LGF20C030001).

\section{Competing Interests}

The authors declare no competing interests.

\section{Availability of data and materials}

The data and materials presented in this study are available on request from the corresponding author. The data are not publicly available due to privacy restrictions.

\section{Acknowledgements}

This research was supported by Zhejiang Provincial Natural Science Foundation of China (LGF20C030001). The authors are very grateful for the support.

\section{References}

Amuda, O.S., Giwa, A.A. and Bello, I.A. 2007. Removal of heavy metal from industrial wastewater using modified activated coconut shell carbon. Biochem. Eng. J., 36: 174-181.

Bacik, D.B., Zhang, M., Zhao, D., Roberts, C.B., Seehra, M.S., Singh, V. and Shah, N. 2012. Synthesis and characterization of supported polysugarstabilized palladium nanoparticle catalysts for enhanced hydrodechlorination of trichloroethylene. Nanotechnology, 23: 294004.

Bostick, B.C., Fendorf, S. and Fendorf, M. 2000. Disulfide disproportionation and $\mathrm{CdS}$ formation upon cadmium sorption on $\mathrm{FeS}_{2}$. Geochem. Cosmochim. Acta, 64: 247-255.

Cao, Z.Z., Mei, L.Q., Xiao, Y.L., Zhi, W.Z. and Ming, X.C. 2018. Sulfur supply 
reduces cadmium uptake and translocation in rice grains (O. sativa L.) by enhancing iron plaque formation, cadmium chelation and vacuolar sequestration. Environ. Pollut., 238:76-84.

Chen, C., Li, X., Zhao, D., Tan, X. and Wang, X. 2007. Adsorption kinetic, thermodynamic and desorption studies of Th(IV) on oxidized multi-wall carbon nanotubes. Colloid Surf. A, 302: 449-454.

Devi, P. and Saroha, A.K. 2014. Synthesis of the magnetic biochar composites for use as an adsorbent for the removal of pentachlorophenol from the effluent. Bioresour. Technol., 169: 525-531.

Duan, X., Su, C., Zhou, L., Sun, H., Suvorova, A., Odedairo, T., Zhu, Z., Shao, Z. and Wang, S. 2016. Surface controlled generation of reactive radicals from persulfate by carbocatalysis on nanodiamonds. Appl. Catal. B-Environ., 194: 7-15.

He, H., Qin, Z. and Shoesmith, D.W. 2010. Characterizing the relationship between hyperstoichiometry, defect structure and local corrosion kinetics of uranium dioxide. Electrochim. Acta, 56: 53-60.

Hedhili, M.N., Yakshinskiy, B.V. and Madey, T.E. 2000. Interaction of water vapor with $\mathrm{UO}_{2}(001)$. Surf. Sci., 445: 512-525.

Hao, M.J., Qiu, M.Q., Yang, H., Hu, B.W. and Wang, X.X. 2021. Recent advances on preparation and environmental applications of MOF-derived carbons in catalysis. Sci. Total Environ. 760: 143333.

Hu, B.W., Guo, X.J., Zheng, C., Song, G., Chen, D.Y., Zhu, Y.L., Song, X.F. and Sun, Y.B. 2019. Plasma-enhanced amidoxime/magnetic graphene oxide for efficient enrichment of U(VI) investigated by EXAFS and modeling techniques. Chem. Eng. J., 357: 66-74.

Hu, B.W., Wang, H.F., Liu, R.R. and Qiu, M.Q. 2021. Highly efficient U(VI) capture by amidoxime/carbon nitride composites: Evidence of EXAFS and modeling. Chemosphere, 274: 129743.

Hua, B. and Deng, B. 2008. Reductive immobilization of uranium(VI) by amorphous iron sulfide. Environ. Sci. Technol., 42: 8703-8708.

Hussain, I., Li, M., Zhang, Y., Li, Y., Huang, S., Du, X., Liu, G., Hayat, W. and Anwar, 
N. 2017. Insights into the mechanism of persulfate activation with nZVI/BC nanocomposite for the degradation of nonylphenol. Chem. Eng. J., 311: 163-171.

Hyun, S.P., Davis, J.A., Sun, K. and Hayes, K.F. 2012. Uranium (VI) reduction by iron (II) monosulfide mackinawite. Environ. Sci. Technol., 46: 3369-3376.

Leite, A.J.B., Lima, E.C., Reis, G.S., Thue, P.S., Saucier, C., Rodembusch, F.S., Dias, S.L.P., Umpierres, C.S. and Dotto, G.L. 2017. Hybrid adsorbents of tannin and APTES (3-aminopropyltriethoxysilane) and their application for the highly efficient removal of acid red 1 dye from aqueous solutions. Chem. Eng. J., 5: 4307-4318.

Li, M.X., Liu, H.B., Chen, T.H., Dong, C. and Sun, Y.B. 2019. Synthesis of magnetic biochar composites for enhanced uranium (VI) adsorption. Sci. Total Environ., 651: 1020-1028.

Liang, T., Han, D., Guodong, W., Jingquan, K., Hongxi, P., Jinyin, L., 2016. Sulfur decreases cadmium translocation and enhances cadmium tolerance by promoting sulfur assimilation and glutathione metabolism in Brassica chinensis L. Ecotoxicol. Environ. Saf., 124: 129-137.

Liu, J., Wan, L., Zhan, L. and Zhou, Q. 2011. Effect of pH, ionic strength, and temperature on the phosphate adsorption onto lanthanum-doped activated carbon fiber. J. Colloid Interf. Sci., 364: 490-496.

Liu, L., Zhang, Z.X., Song, W.C. and Chu, Y.N. 2018. Removal of radionuclide U(VI) from aqueous solution by the resistant fungus Absidia corymbifera. J. Radioanal. Nucl. Chem., 318: 1151-1160.

Lyu, H.H., Gong, Y.Y., Tang, J.S., Huang, Y. and Wang, Q.L. 2016. Immobilization of heavy metals in electroplating sludge by biochar and iron sulfide. Environ. Sci. Pollut. Res., 23: 14472-14488.

Lyu, H.H., Zhao, H., Tang, J.C., Gong, Y.Y., Huang, Y., Wu, Q.H. and Gao, B. 2018. Immobilization of hexavalent chromium in contaminated soils using biochar supported nanoscale iron sulfide composite. Chemophere, 194: 360-369.

Ma, S.L., Huang, L., Ma, L.J., Shim, Y., Islam, S.M., Wang, P.L., Zhao, L.D., Wang, S.C., Sun, G.B., Yang, X.J. and Kanatzidis, M.G. 2015. Efficient uranium capture by polysulfide/layered double hydroxide composites. J. Am. Chem. Soc., 137: 
3670-3677.

Maity, D. and Agrawal, D. 2007. Synthesis of iron oxide nanoparticles under oxidizing environment and their stabilization in aqueous and non-aqueous media. J. Magn. Magn. Mater., 308: 46-55.

Nguyen, V.C. and Pho, Q.H. 2014. Preparation of chitosan coated magnetic hydroxyapatite nanoparticles and application for adsorption of reactive blue 19 and $\mathrm{Ni}^{2+}$ ions. Sci. World J., 14: 273082-273091.

Oliveira, R.C., Hammer, P., Guibal, E., Taulemesse, J.M. and Jr, O.G. 2014. Characterization of metal-biomass interactions in the lanthanum(III) biosorption on Sargassum sp. using SEM/EDS, FTIR, and XPS: preliminary studies. Chem. Eng. J., 239: 381-391.

Pegg, I.L. 2015. Behavior of technetium in nuclear waste vitrification processes. J. Radioanal. Nucl. Chem., 305: 287-292.

Popel, A.J., Adamska, A.M., Martin, P.G., Payton, O.D., Lampronti, G.I., Picco, L., Payne, L., Springell, R., Scott, T.B., Monnet, I., Grygiel, C. and Farnan, I. 2016. Structural effects in $\mathrm{UO}_{2}$ thin films irradiated with $\mathrm{U}$ ions. Nucl. Instr. Meth. Phys. Res. B, 386: 8-15.

Qiu, H., Liang, C., Yu, J., Zhang, Q., Song, M. and Chen, F. 2017. Preferable phosphate sequestration by nano-La(III) (hydr)oxides modified wheat straw with excellent properties in regeneration. Chem. Eng. J., 315: 345-354.

Qiu, M.Q. and Huang, P. 2017. Kinetic and thermodynamic studies on the adsorption of zinc ions from aqueous solution by the blast furnace slag. Nature Environ. Poll. Technol., 16: 639-642.

Qiu, M., Liu, Z., Wang, S. and Hu, B. 2021. The photocatalytic reduction of U(VI) into $\mathrm{U}(\mathrm{IV})$ by $\mathrm{ZIF}-8 / \mathrm{g}-\mathrm{C}_{3} \mathrm{~N}_{4}$ composites at visible light. Environ. Res., 196: 110349 .

Qiu, M.Q., Wang, M., Zhao, Q.Z., Hu, B.W. and Zhu, Y.L. 2018. XANES and EXAFS investigation of uranium incorporation on nZVI in the presence of phosphate. Chemosphere, 201: 764-771.

Rehmana, M.Z., Muhammad, R., Hinnan, K., Shafaqat, A., Asif, N., Balal, Y., Guijian, 
L., Muhammad, S. and Muhammad, F. 2018. Farmyard manure alone and combined with immobilizing amendments reduced cadmium accumulation in wheat and rice grains grown infield irrigated with raw effluents. Chemosphere, 199: 468-476.

Senanayake, S.D. and Idriss, H. 2006. $\mathrm{UO}_{2}$ (III) single crystal: comparison of stoichiometric and defective surfaces by XPS. Surf. Sci. Spec., 13: 72-80.

Sheng, G., Yang, Q., Peng, F., Li, H., Gao, X. and Huang, Y. 2014. Determination of colloidal pyrolusite, $\mathrm{Eu}(\mathrm{III})$ and humic substance interaction: a combined batch and EXAFS approach. Chem. Eng. J., 245: 10-16.

Sheng, G., Li, Y., Dong. H. and Shao, D. 2012. Environmental condition effects on radionuclide $\mathrm{Cu}-64(\mathrm{II})$ sequestration to a novel composite: polyaniline grafted multiwalled carbon nanotubes. J. Radioanal. Nucl. Chem., 293: 797-806.

Shi, Q., Yan, L., Chan, T. and Jing, C. 2015. Arsenic adsorption on lanthanum-impregnated activated alumina: spectroscopic and DFT study. ACS Appl. Mater., 7: 26735-26741.

Sun, Y., Li, H., Li, G., Gao, B., Yue, Q., Li, X. 2016. Characterization and ciprofloxacin adsorption properties of activated carbons prepared from biomass wastes by $\mathrm{H}_{3} \mathrm{PO}_{4}$ activation. Bioresour. Technol., 217: 239-244.

Sun, Y., Li, J. and Wang, X. 2014. The retention of uranium and europium onto sepiolite investigated by macroscopic, spectroscopic and modeling techniques. Geochim. Cosmochim. Acta, 140: 621-643.

Sun, Y., Wu, Z., Wang, X., Ding, C., Cheng, W., Yu, S. and Wang, X. 2016. Macroscopic and microscopic investigation of U(VI) and Eu(III) adsorption on carbonaceous nanofibers. Environ. Sci. Technol., 50: 4459-4467.

Sun, Y., Yang, S., Chen, Y., Ding, C., Cheng, W. and Wang, X. 2015. Adsorption and desorption of $\mathrm{U}(\mathrm{VI})$ on functionalized grapheme oxides: a combined experimental and theoretical study. Environ. Sci. Technol. 49: 4255-4262.

Tan, X., Fan, Q., Wang, X. and Grambow, B. 2009. Eu(III) Sorption to $\mathrm{TiO}_{2}$ (anatase and rutile): batch, XPS, and EXAFS studies. Environ. Sci. Technol., 43: 3115-3121.

Troyer, L.D., Maillot, F., Wang, Z., Wang, Z., Mehta, V.S., Giammar, D.E. and 
Catalano, J.G. 2016. Effect of phosphate on U(VI) sorption to montmorillonite: ternary complexation and precipitation barriers. Geochim. Cosmochim. Acta, 175: 86-99.

Veeramani, H., Alessi, D.S., Suvorova, E.I., Lezama-Pacheco, J.S., Stubbs, J.E., Sharp, J.O., Dippon, U., Kappler, A., Bargar, J.R. and Bernier-Latmani, R. 2011. Products of abiotic U(VI) reduction by biogenic magnetite and vivianite. Geochim. Cosmochim. Acta, 75: 2512-2528.

Wang, H., Zhang, Q., Qiu, M. and Hu, B. 2021. Synthesis and application of perovskite-based photocatalysts in environmental remediation: A review. J. Mol. Liq., 334: 116029.

Wang, X., Chen, Z. and Wang, X. 2015. Graphene oxides for simultaneous highly efficient removal of trace level radionuclides from aqueous solutions. Sci. China Chem., 58: 1766-1773.

Wang, Y., Ji, H., Lu, H., Liu, Y., Yang, R., He, L. and Yang, S. 2018. Simultaneous removal of $\mathrm{Sb}$ (III) and $\mathrm{Cd}(\mathrm{II})$ in water by adsorption onto a $\mathrm{MnFe}_{2} \mathrm{O}_{4}$ biochar nanocomposite. RSC Adv., 8: 3264-3273.

Xu, Q., Pan, D. and Wu, W. 2015. Effects of $\mathrm{pH}$, ionic strength, humic substances and temperature on Th(IV) sorption onto ZSM-5. J. Radioanal Nucl. Chem., 305: $535-541$.

Yang, J., Pan, B., Li, H., Liao, S., Zhang, D., Wu, M. and Xing, B. 2016. Degradation of p-nitrophenol on biochars: role of persistent free radicals. Environ. Sci. Technol., 50: 694-700.

Yao, W., Wu, Y., Pang, H., Wang, X., Yu, S. and Wang, X. 2018. In-situ reduction synthesis of manganese dioxide@polypyrrole core/shell nanomaterial for highly efficient enrichment of U(VI) and Eu(III). Sci. China Chem., 61: 812-823.

Yen, M.Y., Teng, C.C., Hsiao, M.C., Liu, P.I., Chuang, W.P., Ma, C.C.M., Hsieh, C.K., Tsai, M.C. and Tsai, C.H. 2011. Platinum nanoparticles/graphene composite catalyst as a novel composite counter electrode for high performance dye-sensitized solar cells. J. Mater. Chem., 21: 12880-12905.

Yu, A., Teterin, A.J., Popel, K.I., Maslakov, A.Y., Teterin, K.E., Ivanov, S.N., 
Kalmykov, R., Springell, T.B. and Scott, I.F. 2016. XPS study of ion irradiated and unirradiated $\mathrm{UO}_{2}$ thin films, Inorg. Chem., 55: 8059-8070.

Yu, S.M., Chen, C.L., Chang, P.P., Wang, T.T., Lu, S.S. and Wang, X.K. 2008. Adsorption of Th(IV) onto Al-pillared rectorite: effect of $\mathrm{pH}$, ionic strength, temperature, soil humic acid and fulvic acid. Appl. Clay Sci., 38: 219-226.

Zhang, H.X., Wang, X.Y., Liang, H.H., Tan, T. and Wu, W.S. 2016. Adsorption behavior of Th(IV) onto illite: Effect of contact time, $\mathrm{pH}$ value, ionic strength, humic acid and temperature. Appl. Clay Sci., 127-128: 35-43.

Zhang, L., Qin, X., Tang, J., Liu, W. and Yang, H. 2016. Review of arsenic geochemical characteristics and its significance on arsenic pollution studies in karst groundwater, Southwest China. Appl. Geochem., 77: 80-88.

Zhang, Q., Wang, Y.Y., Wang, Z., Zhang, Z.J., Wang, X.D. and Yang, Z.L. 2021. Active biochar support nano zero-valent iron for efficient removal of U(VI) from sewage water. J. Alloy. Compd., 852: 156993.

Zhang, X., Yang, Y., Guo, S., Hu, F. and Liu, L. 2015. Mesoporous Ni0.85Se nanospheres grown in situ on graphene with high performance in dye-sensitized solar cells. ACS Appl. Mater. Interf., 7: 8457-8464.

Zou, J., Ma, J., Chen, L., Li, X., Guan, Y., Xie, P. and Pan, C. 2013. Rapid acceleration of ferrous iron/peroxymonosulfate oxidation of organic pollutants by promoting $\mathrm{Fe}(\mathrm{III}) / \mathrm{Fe}(\mathrm{II})$ cycle with hydroxylamine. Environ. Sci. Technol., 47: $11685-11691$. 


\section{Supplementary Files}

This is a list of supplementary files associated with this preprint. Click to download.

- Supplementmaterials.docx 